\title{
Anti-proliferative and pro-apoptotic effects of rosemary and constituent terpenoids in a model for the HER-2-enriched molecular subtype of clinical breast cancer
}

\author{
NITIN TELANG \\ Cancer Prevention Research Program, Palindrome Liaisons Consultants, Montvale, NJ 07645-1559, USA
}

Received March 16, 2018; Accepted June 15, 2018

DOI: $10.3892 / \mathrm{ol} .2018 .9238$

\begin{abstract}
Neoadjuvant treatment options for human epidermal growth factor receptor-2 (HER-2)-enriched and luminal B molecular subtypes of clinical breast cancer include HER-2-targeted therapy with chemotherapy or anti-hormonal therapy. These treatment options result in systemic toxicity and acquired tumor resistance. Minimally toxic naturally occurring phytochemicals may represent testable alternatives to conventional therapy. HER-2-overexpressing tumorigenic human mammary epithelial 184-B5/HER cells represent a model for the HER-2-enriched breast cancer subtype. Non-fractionated rosemary extract (RME) and constituent phenolic terpenoids ursolic acid (UA), carnosol (CSOL) and carnosic acid (CA) represented the test agents. Anchorage-independent (AI) proliferation, cell cycle progression, cellular apoptosis and expression of cell cycle-regulatory and apoptosis-specific proteins represented the mechanistic end point biomarkers. Relative to the parental non-tumorigenic 184-B5 cells, tumorigenic 184-B5/HER cells exhibited decreased population doubling, increased saturation density, accelerated cell cycle progression and downregulated cellular apoptosis, confirming the loss of homeostatic control of proliferation. Treatment with the test agents resulted in a dose-dependent decrease in AI colony number, indicating a decrease in cancer risk. Mechanistically, RME and UA inhibited $\mathrm{G}_{1}-\mathrm{S}$ phase transition resulting in an increased $\mathrm{G}_{1}: \mathrm{S}+\mathrm{G}_{2} / \mathrm{M}$ ratio and decreased cyclin D1 expression. The pro-apoptotic effect of RME and UA was indicated by increased sub- $\mathrm{G}_{0}$ (apoptotic) cell population, and relevant reciprocal modulation, as demonstrated by decreased anti-apoptotic B-cell lymphoma-2 (Bcl-2) and increased pro-apoptotic Bcl-2-associated X protein expression. In contrast, treatment with $\mathrm{CA}$ and $\mathrm{CSOL}$ resulted in cytostatic $\mathrm{G}_{2} / \mathrm{M}$ arrest and an increase in cyclin
\end{abstract}

Correspondence to: Professor Nitin Telang, Cancer Prevention Research Program, Palindrome Liaisons Consultants, 10 Rolling Ridge Road, Montvale, NJ 07645-1559, USA

E-mail: ntelang3@gmail.com

Key words: human epidermal growth factor receptor-2 expression, rosemary terpenoids, proliferation inhibition
B1 expression; thus, naturally-occurring rosemary and its constitutive terpenoids re-establish homeostatic control of proliferation and decrease cancer risk via distinct mechanisms. These data validate an experimental approach to prioritize efficacious natural compounds as testable alternatives for conventional chemo-endocrine and HER-2-targeted therapies in HER-2-enriched breast cancer.

\section{Introduction}

Genetically defined molecular subtypes of clinical breast cancer facilitate the accurate prediction of disease progression and rational selection of targeted therapeutic options. Expression of human epidermal growth factor receptor-2 (HER-2) on a background of estrogen receptor- $\alpha(E R \alpha)$ and progesterone receptor (PR) positivity or negativity dictates distinct therapeutic options. These options are frequently associated with systemic toxicity, acquired tumor resistance and emergence of drug-resistant cancer stem cells favoring progression of therapy-resistant disease (1).

Targeted expression of HER-2, Ras and Myc oncogenes confers tumorigenic transformation in mammary epithelial cells (2-4). In the clinic, amplification of HER-2 in the presence of ER $\alpha$ and PR expression (luminal B subtype) or in the absence of their expression (HER-2-enriched subtype) dictate distinct therapeutic options, including antibody and/or small-molecule inhibitor-based HER-2-targeted therapy with or without hormone receptor- and/or aromatase inhibitor-based endocrine therapy (5-7).

Naturally occurring phytochemicals and herbal extracts that exhibit minimal systemic toxicity may represent testable alternatives to conventional chemo-endocrine therapy for treating breast cancer in the clinic $(8,9)$. Published evidence on a model for HER-2-enriched breast cancer has demonstrated potent anti-proliferative and pro-apoptotic effects of a number of mechanistically distinct naturally occurring compounds, including phytoalexins $(10)$, isoflavones $(11,12)$, vitamin A derivatives (13) and phenolic terpenoids $(14,15)$.

Rosemary (Rosemarinus officinalis L.) is a herb that is frequently used as a dietary spice and also exhibits medicinal properties. Rosemary and its constituent terpenoids are potent anti-inflammatory agents that inhibit chronic dermal inflammation, and skin tumor initiation and promotion $(16,17)$; however, there is limited knowledge regarding the effects of rosemary 
and its constituent terpenoids in breast cancer, where expression of HER-2 oncogene has a negative effect on endocrine therapy.

The present study utilized a cellular model of human mammary epithelial cells that were tumorigenic owing to targeted expression of the HER-2 oncogene. These tumorigenic cells lack the expression of ERs and PRs, thus the expression of HER-2 on ER $\alpha$ - and PR-negative background provides a model for HER-2-enriched breast cancer. Experiments in the present study were designed to: i) Characterize the model at cellular and molecular level; ii) examine the proliferation inhibitory effects of rosemary and its constituent phenolic terpenoids; and iii) identify potential molecular mechanisms responsible for proliferation inhibitory efficacy.

\section{Materials and methods}

Cell lines. 184-B5 is a triple negative human mammary epithelial cell line that lacks the expression of $\mathrm{ER} \alpha, \mathrm{PR}$ and HER-2, and is non-tumorigenic (18). 184-B5/HER is a cell line derived from parental 184-B5 cells that are stably transfected with the HER-2 oncogene. These HER-2-expressing cells exhibit tumorigenic transformation (19). The two cell lines were obtained from Professor Clifford W. Welsch (Michigan State University, East Lansing, MI, USA). These cell lines were grown in Dulbecco's modified Eagle's medium: Nutrient mixture F12 (DME-F12; Gibco; Thermo Fisher Scientific, Inc., Waltham, MA, USA), supplemented with $10 \mathrm{ng} / \mathrm{ml}$ epidermal growth factor, $0.5 \mu \mathrm{g} / \mathrm{ml}$ hydrocortisone, $10 \mu \mathrm{g} / \mathrm{ml}$ transferrin, $10 \mu \mathrm{g} / \mathrm{ml}$ insulin and $5 \mu \mathrm{g} / \mathrm{ml}$ gentamicin (all from Sigma-Aldrich; Merck KGaA, Darmstadt, Germany). The 184-B5/HER cells were routinely maintained in the presence of $200 \mu \mathrm{g} / \mathrm{ml} \mathrm{G} 418$ (Geneticin ${ }^{\circledR}$; Sigma-Aldrich; Merck KGaA) to eliminate the expression of spontaneous revertants. The cell cultures were maintained at $37^{\circ} \mathrm{C}$ in humidified atmosphere containing $95 \%$ air and $5 \% \mathrm{CO}_{2}$, and were sub-cultured at $80 \%$ confluency.

Test agents. Non-fractionated extract from rosemary leaves (RME) and carnosol (CSOL; molecular mass 330.42 Da) were provided by Nestlé Research Center (Lausanne, Switzerland). Ursolic acid (UA; molecular mass 456.70 Da) and carnosic acid (CA; molecular mass $332.43 \mathrm{Da}$ ) were purchased from Sigma-Aldrich; Merck KGaA. RME contained 20-30\% UA, 15-20\% CSOL and 10-15\% CA. The stock solution of RME was prepared in dimethyl sulfoxide (DMSO; Sigma-Aldrich; Merck $\mathrm{KGaA}$ ) at a concentration of $10 \mathrm{mg} / \mathrm{ml}$. The stock solutions of UA, CA and CSOL were prepared in DMSO at concentrations of $10 \mathrm{mM}$. These stock solutions were serially diluted in DMEM-F12 culture medium to obtain final concentrations of 2, 5 and $10 \mu \mathrm{g} / \mathrm{ml} \mathrm{RME;} 1,5$ and $10 \mu \mathrm{M} \mathrm{UA}$ and CA; and 1,2.5 and 5.0 $\mu \mathrm{M}$ CSOL. These final concentrations were used for dose-response experiments on 184-B5/HER cells to identify the half-maximal inhibitory concentration $\left(\mathrm{IC}_{50}\right)$ and the maximum effective inhibitory concentration $\left(\mathrm{IC}_{90}\right)$.

Antibodies. The human reactive fluorescein isothiocyanate (FITC)-conjugated antibodies anti-B-cell lymphoma-2 (Bcl-2; cat. no. F7053) and anti-cyclin B1 (cat. no. F0169) were purchased from Dako; Agilent Technologies, Inc. (Santa Clara, CA, USA). Anti-human epidermal growth factor receptor-2 (HER-2; cat. no. SC7301), anti-epidermal growth factor receptor (EGFR; cat. no. SC101), anti-Bcl-2-associated X (Bax; cat. no. SC20067), anti-estrogen receptor- $\alpha$ (ER- $\alpha$; cat. no. SC787) and anti-progesterone receptor (PR; cat. no. SC166169) were purchased from Santa Cruz Biotechnology, Inc. (Santa Cruz, CA, USA). Anti-cyclin D1 (cat. no. BDB554109) was purchased from BD Biosciences, Inc. (San Jose, CA, USA). These antibodies were used according to the recommended dilutions provided in the technical protocols from the suppliers in the present experiments to monitor the status of relevant proteins.

Proliferation assays. Population doubling times, saturation density, cell cycle progression and anchorage-independent (AI) colony formation were determined for the aforementioned cell lines following previously published optimized protocols $(11,13)$. Population doubling times were determined from independent $24 \mathrm{~h}$ viable cell counts during the exponential phase for 4 days. Saturation density was determined from viable cell counts at day 7 post-seeding of $1 \times 10^{5}$ cells. The viable cell counts were determined by the trypan blue exclusion test using a hemocytometer. Cell cycle progression and cellular apoptosis were determined by flow-cytometer-based fluorescence-activated cell sorting using an EPICS 752 flow cytometer (Beckman Coulter, Inc., Miami, FL, USA). The data on distribution of the cell population in $\mathrm{G}_{1}, \mathrm{~S}, \mathrm{G}_{2} / \mathrm{M}$ and sub $\mathrm{G}_{0}$ phases of the cell cycle was analyzed using the multi-cycle MPLUS software version 2.0 (Phoenix Flow Systems, San Diego, CA, USA), and the data are presented as the $G_{1}: S+G_{2} / M$ phase ratio and the incidence of sub- $\mathrm{G}_{0}$ cell population. These data indicate the status of relative proportion of quiescent compared with proliferating cells, and the incidence of apoptotic cells. For the AI colony formation assay, 1,000 cells were suspended in $0.33 \%$ agar, overlaid on a basement matrix of $0.6 \%$ agar and maintained in culture for 21 days. The AI colony formation was then quantified by determining the number of colonies under an inverted light microscope at magnification, $\mathrm{x} 10$.

Cellular immunofluorescence assay. The cellular immunofluorescence was quantified in 184-B5 and 184-B5/HER cells stained with FITC-conjugated antibodies following the previously published optimized protocol $(11,13)$. Briefly, the cell suspension was fixed in $0.25 \%$ buffered paraformaldehyde (Polysciences, Inc., Warrington, PA, USA) made up in PBS (pH 7.4, Sigma-Aldrich; Merck KGaA, Darmstadt Germany) for $30 \mathrm{~min}$ on ice. The fixed cell suspension was subsequently incubated with $0.1 \%$ Triton X-100 (Sigma-Aldrich; Merck $\mathrm{KGaA}$ ) on ice for $3 \mathrm{~min}$ to permeabilize the cell membrane. The permeabilized cells were washed twice with PBS ( $\mathrm{pH} 7.4$ ), and stained with the appropriate FITC-conjugated antibodies. Antibody stained 184-B5 and 184-B5/HER cells were monitored for antibody expression by fluorescence-activated cell sorting using a flow cytometer. Cells stained with isotype FITC-conjugated IgG represented the negative controls. The experimental data were corrected for FITC IgG and are presented as log mean fluorescence units (FU) per $1 \times 10^{5}$ fluorescence events.

Statistical analysis. Experiments for population doubling, saturation density, cell cycle progression and antibody-based immunofluorescence were performed in duplicate $(n=6$ per 
Table I. Status of homeostatic control of proliferation and cancer risk in 184-B5/HER cells.

\begin{tabular}{|c|c|c|c|}
\hline \multirow[b]{2}{*}{ Biomarker } & \multicolumn{2}{|c|}{ Cell line } & \multirow[b]{2}{*}{ Relative to184-B5 cells (\%) } \\
\hline & 184-B5 & 184-B5/HER & \\
\hline Population doubling ${ }^{\mathrm{a}}$ & $34.1 \pm 1.7 \mathrm{~h}$ & $15.2 \pm 4.1 \mathrm{~h}^{\mathrm{e}}$ & -55.4 \\
\hline Saturation density ${ }^{\mathrm{b}}$ & $23.7 \pm 1.3 \times 10^{5}$ & $38.2 \pm 1.7 \times 10^{5 \mathrm{e}}$ & +61.2 \\
\hline $\mathrm{G}_{1}: \mathrm{S}+\mathrm{G}_{2} / \mathrm{M}$ ratio $^{\mathrm{c}}$ & $1.8 \pm 0.3$ & $0.8 \pm 0.1^{\mathrm{e}}$ & -55.6 \\
\hline$\%$ Sub $-\mathrm{G}_{0}^{\mathrm{c}}$ & $18.9 \pm 2.6$ & $0.6 \pm 0.2^{\mathrm{f}}$ & -96.8 \\
\hline \multicolumn{4}{|l|}{ AI colony formation ${ }^{\mathrm{d}}$} \\
\hline Incidence & $0 / 18$ & $18 / 18$ & \\
\hline Mean colony number & - & $25.8 \pm 4.6$ & \\
\hline
\end{tabular}

${ }^{a}$ Determined from cells in exponential phase. ${ }^{b}$ Determined from the viable cell number at day 7 post-seeding of $1.0 \times 10^{5}$ cells. ${ }^{\mathrm{c}}$ Determined from fluorescence-activated cell sorting. Results are presented as the mean $\pm \mathrm{SD}, \mathrm{n}=6$ per biomarker. ${ }^{\mathrm{d}}$ Determined at day 21 post-seeding of 1,000 cells. Results are presented as the mean $\pm \mathrm{SD}, \mathrm{n}=18$ per treatment group. ${ }^{\mathrm{e}} \mathrm{P}=0.04$; ${ }^{\mathrm{f}} \mathrm{P}=0.02$ vs. $184-\mathrm{B} 5$ cells. AI, anchorage-independent; $\mathrm{SD}$, standard deviation.

Table II. Status of molecular markers in 184-B5/HER cells.

\begin{tabular}{|c|c|c|c|}
\hline \multirow{2}{*}{$\begin{array}{l}\text { Molecular } \\
\text { marker }\end{array}$} & \multicolumn{2}{|c|}{ Cell line } & \multirow{2}{*}{$\begin{array}{c}\text { Relative to } \\
\text { 184-B5 cells }(\%)\end{array}$} \\
\hline & $184-\mathrm{B5}^{\mathrm{a}}$ & 184-B5/HER ${ }^{\mathrm{a}}$ & \\
\hline $\mathrm{ER} \alpha$ & ND & ND & \\
\hline PR & ND & ND & \\
\hline HER-2 & $0.3 \pm 0.1$ & $53.8 \pm 2.5^{b}$ & $+17,830.0$ \\
\hline EGFR & $13.9 \pm 3.7$ & $8.3 \pm 2.2$ & -40.3 \\
\hline Bcl-2 & $62.2 \pm 5.7$ & $80.5 \pm 5.1^{\mathrm{c}}$ & +29.4 \\
\hline Bax & $59.8 \pm 3.3$ & $26.6 \pm 2.7^{\mathrm{d}}$ & -55.5 \\
\hline
\end{tabular}

${ }^{\mathrm{a} F I T C-c o n j u g a t e d ~ a n t i b o d y-b a s e d ~ c e l l u l a r ~ i m m u n o f l u o r e s c e n c e . ~}$ Results are presented as $\log$ mean $\mathrm{FU} \pm$ standard deviation, $\mathrm{n}=6$ per treatment group. Data corrected for FU from FITC-conjugated IgG. ND, Non-detectable. Comparable FU in antibody-stained and IgG-stained cells. ${ }^{\mathrm{b}} \mathrm{P}=0.01,{ }^{\mathrm{C}} \mathrm{P}=0.04,{ }^{\mathrm{d}} \mathrm{P}=0.03$ vs. 184 -B5 cells. $\mathrm{ER} \alpha$, estrogen receptor- $\alpha$; PR, progesterone receptor; HER-2, human epidermal growth factor receptor-2; EGFR, epidermal growth factor receptor; Bcl-2, B-cell lymphoma-2; Bax, Bcl-2 associated X protein; FITC, Fluorescein isothiocyanate; FU, fluorescence units.

treatment group). Experiments for AI colony formation were performed in triplicate ( $n=18$ per treatment group). The data are presented as the mean \pm standard deviation, and were analyzed for statistical significance between control and experimental groups using an unpaired two-sample Student's t-test using GraphPad Prism software (version 5.0; GraphPad Software, Inc., La Jolla, CA USA). P $<0.05$ was considered to indicate a statistically significant difference. Data comparing multiple treatment groups were analyzed by one-way analysis of variance and Dunnett's multiple range test, with a threshold of $\alpha=0.05$.

\section{Results}

Proliferation characterization of the 184-B5/HER model. Experiments designed to examine the status of proliferation and cancer risk compared selected proliferation parameters in non-tumorigenic 184-B5 and tumorigenic 184-B5/HER cells (Table I). In comparison with 184-B5 cells, 184-B5/HER cells exhibited a $55.4 \%$ decrease $(\mathrm{P}=0.04)$ in population doubling time and a $61.2 \%$ increase $(\mathrm{P}=0.04)$ in saturation density. Additionally, these cells exhibited a $55.6 \%$ decrease $(P=0.04)$ in the $G_{1}: S+G_{2} / M$ ratio and a $96.8 \%$ decrease $(\mathrm{P}=0.02)$ in the sub- $\mathrm{G}_{0}$ cell population. Furthermore, unlike 184-B5 cells, 184-B5/HER cells exhibited a high incidence of AI colony formation.

The data presented in Table II compare the status of selected cell-cycle-regulatory and apoptosis-specific gene products in 184-B5 and 184-B5/HER cells. The two cell lines lacked the expression of ER $\alpha$ and PR. Tumorigenic 184-B5/HER cells exhibited a $17,830 \%$ (178.3 fold) increase $(\mathrm{P}=0.01)$ in HER-2 expression. Additionally, the expression of anti-apoptotic $\mathrm{Bcl}-2$ was increased by $29.4 \%$ ( $\mathrm{P}=0.04)$, whereas pro-apoptotic Bax was decreased by $55.5 \%(\mathrm{P}=0.03)$.

Effects of RME and constituent terpenoids on AI colony formation. Data from experiments designed to examine the effect of RME, CA, CSOL and UA on AI colony formation in 184-B5/HER cells are presented in Table III. A 21-day treatment with these agents resulted in a dose-dependent decrease in the number of AI colonies. The rank order of inhibitory efficacy at $\mathrm{IC}_{50}$ concentration $(\alpha=0.05)$ for individual agents was $\mathrm{CSOL}>\mathrm{CA}>\mathrm{RME}>\mathrm{UA}$.

Inhibition of cell cycle progression. Data from experiments designed to examine the effect of RME and UA on the cell cycle progression of 184-B5/HER cells are presented in Fig. $1 \mathrm{~A}$ and $\mathrm{B}$. Relative to the $\mathrm{G}_{1}: \mathrm{S}+\mathrm{G}_{2} / \mathrm{M}$ ratio of $1.2 \pm 0.3$ in response to treatment with DMSO, treatment with $\mathrm{RME}$ and UA demonstrated a ratio of $2.8 \pm 0.7(\mathrm{P}=0.02)$ and $1.7 \pm 0.4$ $(\mathrm{P}=0.04)$, respectively; thus, a $24 \mathrm{~h}$ treatment with high doses of RME and UA induced a 1.3-fold increase and a $41.7 \%$ increase in the $G_{1}: S+G_{2} / M$ ratio, respectively (Fig. 1A). Relative to cyclin D1 expression of 14.7 \pm 2.1 FU in DMSO-treated cells, treatment with RME and UA exhibited FU values of 4.6 41.2 
Table III. Inhibition of AI colony formation in 184-B5/HER cells.

\begin{tabular}{|c|c|c|c|c|}
\hline Treatment & Concentration & Number of AI colonies $^{\mathrm{a}}$ & Inhibition (\% solvent control) & $\mathrm{IC}_{50}$ \\
\hline DMSO & $0.1 \%$ & $28.3 \pm 6.6^{\mathrm{b}}$ & - & \\
\hline $\mathrm{RME}$ & $\begin{array}{c}2 \mu \mathrm{g} / \mathrm{ml} \\
5 \mu \mathrm{g} / \mathrm{ml} \\
10 \mu \mathrm{g} / \mathrm{ml}\end{array}$ & $\begin{array}{c}20.5 \pm 5.2 \\
12.8 \pm 3.2^{b} \\
2.6 \pm 0.6\end{array}$ & $\begin{array}{l}27.6 \\
54.7 \\
91.8\end{array}$ & 4.6 \\
\hline UA & $\begin{array}{c}1 \mathrm{Mm} \\
5 \mu \mathrm{M} \\
10 \mu \mathrm{M}\end{array}$ & $\begin{array}{c}22.1 \pm 5.6 \\
13.9 \pm 3.4^{\mathrm{c}} \\
2.8 \pm 0.6\end{array}$ & $\begin{array}{l}21.6 \\
50.9 \\
90.1\end{array}$ & 4.9 \\
\hline CA & $\begin{array}{c}1 \mu \mathrm{M} \\
5 \mu \mathrm{M} \\
10 \mu \mathrm{M}\end{array}$ & $\begin{array}{c}18.4 \pm 4.6 \\
11.5 \pm 2.9^{\mathrm{d}} \\
2.3 \pm 0.5\end{array}$ & $\begin{array}{l}34.9 \\
59.4 \\
93.6\end{array}$ & 4.2 \\
\hline CSOL & $\begin{array}{c}1 \mu \mathrm{M} \\
2.5 \mu \mathrm{M} \\
5.0 \mu \mathrm{M}\end{array}$ & $\begin{array}{c}22.6 \pm 5.7 \\
14.1 \pm 3.5^{\mathrm{e}} \\
2.8 \pm 0.6\end{array}$ & $\begin{array}{l}20.1 \\
50.2 \\
90.1\end{array}$ & 2.5 \\
\hline
\end{tabular}

Results are presented as number of AI colonies mean \pm standard deviation, $n=18$ per treatment group. $\alpha=0.05$. ${ }^{a}$ Determined at day 21 post-seeding of 1,000 cells. ${ }^{b} \mathrm{DMSO}>\mathrm{RME}, \alpha=0.05$. ${ }^{\mathrm{c}} \mathrm{DMSO}>\mathrm{UA}, \alpha=0.05$. ${ }^{\mathrm{d}} \mathrm{DMSO}>\mathrm{CA}, \alpha=0.05$. ${ }^{\mathrm{e}} \mathrm{DMSO}>\mathrm{CSOL}, \alpha=0.05$. Data were analyzed by one-way analysis of variance and Dunnett's multiple range test $(\alpha=0.05)$. AI, anchorage-independent; DMSO, dimethyl sulfoxide; $\mathrm{RME}$, rosemary extract; UA, ursolic acid; $\mathrm{CA}$, carnosic acid; $\mathrm{CSOL}$, carnosol; $\mathrm{IC}_{50}$, half maximal inhibitory concentration.

$(P=0.03)$, and 2.2 $\pm 0.6(P=0.03)$, respectively; thus, $G_{1}$ phase arrest induced by RME and UA was associated with a $68.7 \%$ decrease and an $85 \%$ decrease in $\mathrm{G}_{1}$-specific cyclin $\mathrm{D} 1$ expression, respectively (Fig. 1B).

Induction of cellular apoptosis. Data from experiments designed to examine the effect of RME and UA on cellular apoptosis are presented in Fig. 2A and B. Relative to the sub- $\mathrm{G}_{0}$ population of $0.6 \pm 0.3 \%$ in DMSO-treated cells, treatment with RME and UA demonstrated a sub- $\mathrm{G}_{0}$ population of $6.3 \pm 1.6 \%(\mathrm{P}=0.01)$ and $14.0 \pm 2.9 \%(\mathrm{P}=0.01)$, respectively; thus, a $24 \mathrm{~h}$ treatment with RME and UA resulted in a 9.5and 22.3-fold increase, respectively (Fig. 2A). Relative to the Bcl-2 expression of 69.2 $\pm 5.7 \mathrm{FU}$ in DMSO-treated cells, treatment with RME and UA demonstrated FU values of $41.5 \pm 1.8$ $(\mathrm{P}=0.04)$ and $13.2 \pm 1.9(\mathrm{P}=0.02)$, respectively; thus, induction of cellular apoptosis was associated with a $40 \%$ and $80.9 \%$ decrease in the expression of the anti-apoptotic $\mathrm{Bcl}-2$ protein, respectively. In contrast, relative to the Bax expression of 12.8 $\pm 3.7 \mathrm{FU}$ in DMSO-treated cells, treatment with RME and UA demonstrated FU values of $26.9 \pm 1.4(\mathrm{P}=0.02)$ and $39.6 \pm 1.7(\mathrm{P}=0.02)$, respectively; thus, $\mathrm{RME}$ - and UA-treated cells exhibited a 1.1-fold and 2.1-fold increase in the expression of the pro-apoptotic Bax protein, respectively (Fig. 2B).

Regulation of cell cycle progression. The effects of CA and CSOL on cell cycle progression are presented in Fig. 3A and B. Relative to the $\mathrm{G}_{2} / \mathrm{M}$ population of $17.5 \pm 2.6 \%$ in DMSO-treated cells, treatment with $\mathrm{CA}$ and CSOL demonstrated a $\mathrm{G}_{2} / \mathrm{M}$ population of $40.0 \pm 1.7 \%(\mathrm{P}=0.03)$ and $36.0 \pm 1.7 \%(\mathrm{P}=0.03)$, respectively; thus, these treatments resulted in a 1.3 -fold and a 1.0-fold increase of cell population in the $\mathrm{G}_{2} / \mathrm{M}$ phase of the cell cycle (Fig. 3A). Relative to cyclin B1 expression of 13.0 \pm 3.7 FU in DMSO-treated cells, treatment with CA and CSOL demonstrated FU values of $27.0 \pm 1.5(\mathrm{P}=0.02)$ and $24.0 \pm 1.3$ $(\mathrm{P}=0.02)$, respectively; thus, consistent with arrest of cells in the $\mathrm{G}_{2} / \mathrm{M}$ phase of the cell cycle, $\mathrm{CA}$ - and CSOL-treated cells exhibited a 1.1-fold and $84.6 \%$ increase in the expression of the $\mathrm{G}_{2}$-specific cyclin B1, respectively (Fig. 3B).

\section{Discussion}

The hormone receptor-positive, HER-2-expressing breast cancer (luminal B) molecular subtype is primarily treated using HER-2-targeted therapy and conventional endocrine therapy, including selective estrogen receptor modulators, selective estrogen receptor degraders and aromatase inhibitors. Hormone receptor-negative HER-2-expressing breast cancer is primarily treated with HER-2-targeted therapy and conventional chemotherapy, including anthracyclines and taxanes. These long-term treatment options are associated with systemic toxicity and acquired tumor resistance that compromise treatment efficacy and favor drug-resistant disease progression (5-7,20). These limitations emphasize the importance of identifying novel, less toxic treatment options for chemo-endocrine therapy-resistant breast cancer. The present study utilized a cellular model for HER-2-enriched breast cancer to examine the proliferation inhibitory effects of RME and its constituent naturally occurring terpenoids, and to identify potential mechanisms of action for their efficacy.

Comparative experiments on non-tumorigenic 184-B5 cells and tumorigenic 184-B5/HER cells provided evidence that relative to 184-B5 cells, 184-B5/HER cells exhibited hyper-proliferation, accelerated cell cycle progression, downregulated cellular apoptosis and a high incidence of AI colony formation, the latter representing an in vitro surrogate endpoint marker for in vivo tumorigenic transformation. Notably, tumorigenic potential and AI colony formation have 
A

\section{$\mathrm{G}_{1}: \mathrm{S}+\mathrm{G}_{2} / \mathrm{M}$ Ratio}

\section{3}

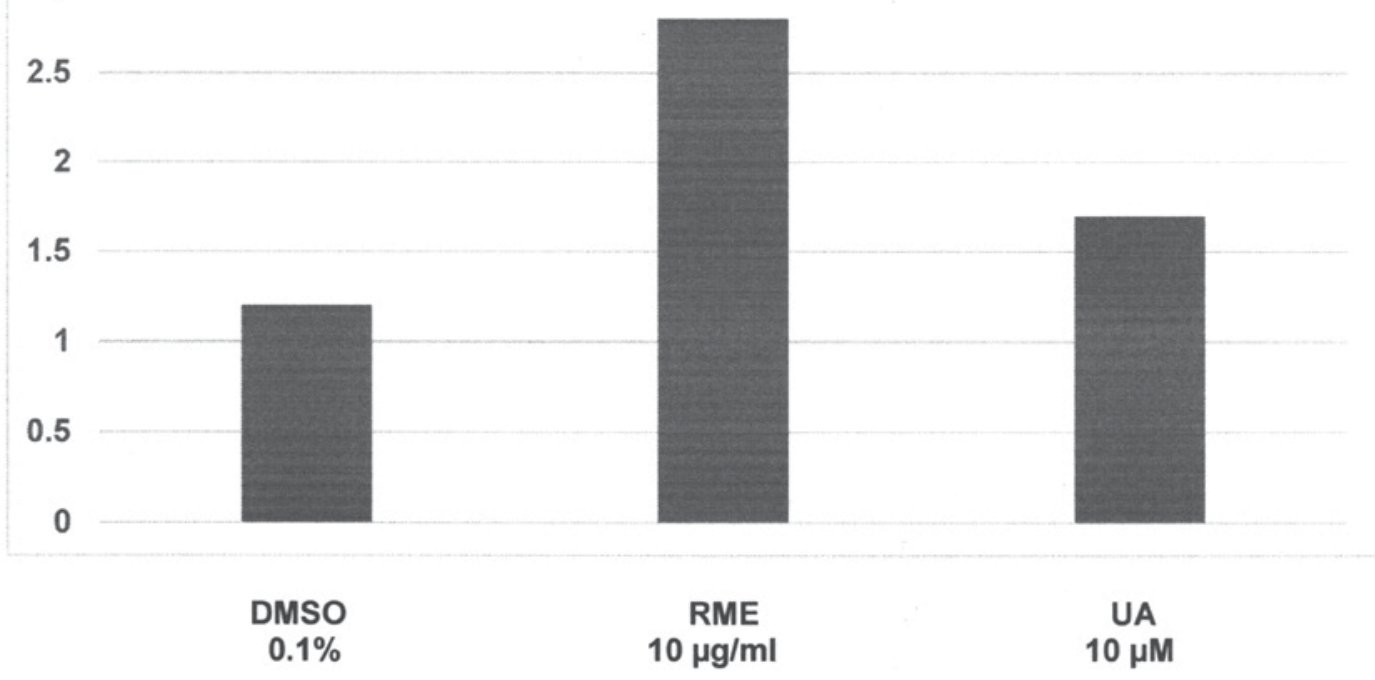

B

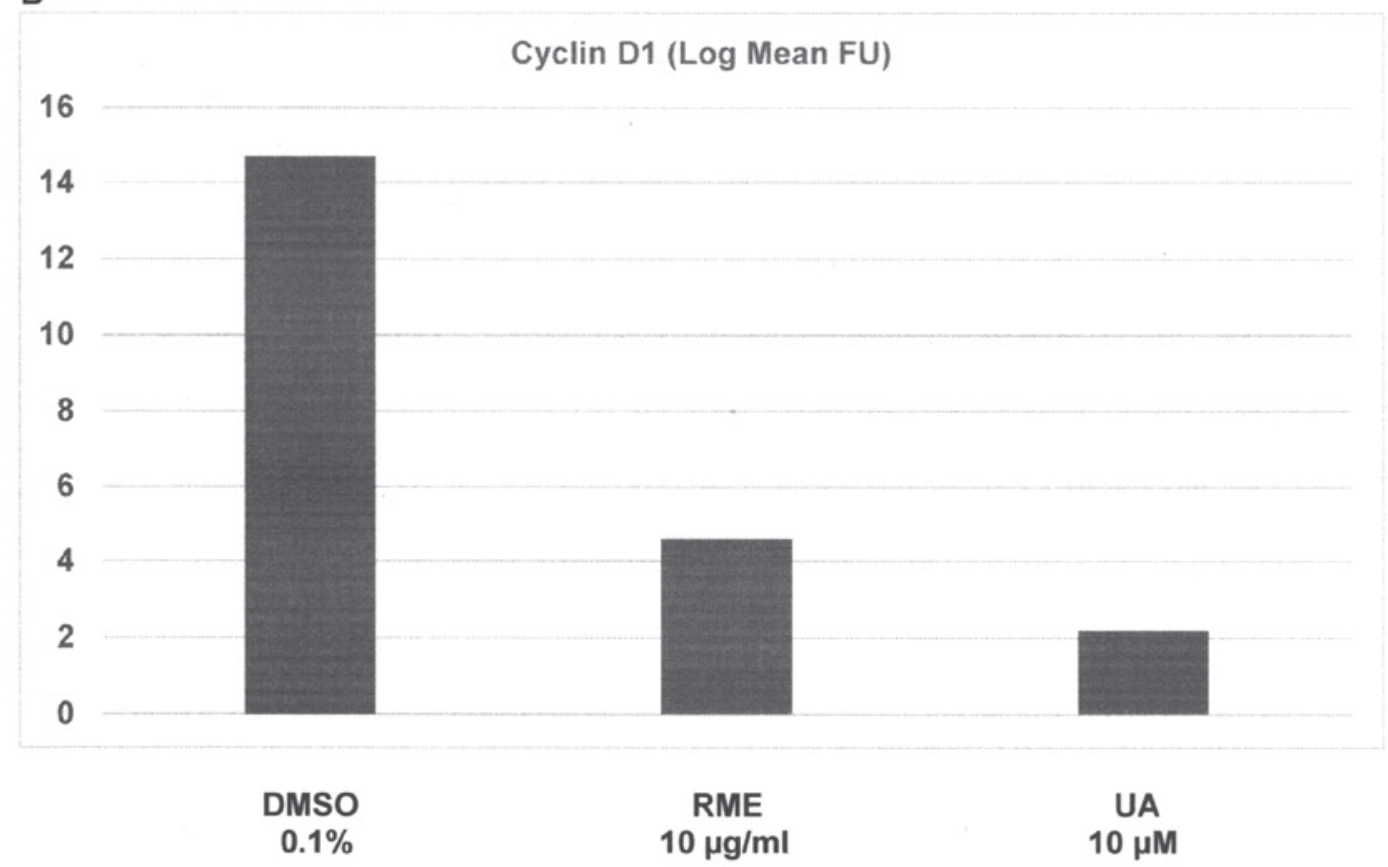

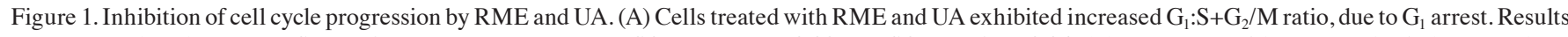
are presented as the mean $\pm \mathrm{SD}, \mathrm{n}=6$ per treatment group. DMSO vs. RME $\mathrm{P}=0.02$, DMSO vs. UA P=0.04. (B) Treatment with RME and UA downregulates the $\mathrm{G}_{1}$ phase-specific cyclin $\mathrm{D} 1$. Results are presented as the $\log$ mean $\mathrm{FU} \pm \mathrm{SD}, \mathrm{n}=6$ per treatment group. $\mathrm{DMSO}$ vs. $\mathrm{RME}, \mathrm{P}=0.03$; $\mathrm{DMSO}$ vs. $\mathrm{UA}, \mathrm{P}=0.03$. FU, fluorescence units; DMSO, dimethyl sulfoxide; RME, rosemary extract; UA, ursolic acid; SD, standard deviation.

been indicated to have a positive correlation for experimentally induced tumorigenic transformation in human mammary epithelial cells $(2,19,21)$. Additionally, AI colony formation is detectable in cellular models for luminal A and triple negative molecular subtypes for clinical breastcancer (22,23). Collectively, these data provide evidence that AI colony formation represents an in vitro surrogate endpoint for tumorigenic transformation and an indicator for cancer risk; thus, these data indicate the loss of homeostatic control of proliferation and persistence of cancer risk. At the molecular level, 184-B5/HER cells exhibited modulated expression of HER-2 and EGFR. Furthermore, HER-2-expressing cells exhibited upregulation of anti-apoptotic Bcl-2 and downregulation of pro-apoptotic Bax. These molecular data may facilitate identification of potential targets for the proliferation inhibitory efficacy of novel anticancer compounds.

Experiments designed to examine the effects of RME and its constituent terpenoids CA, CSOL and UA on AI colony formation in 184-B5/HER cells indicated that these agents 
A

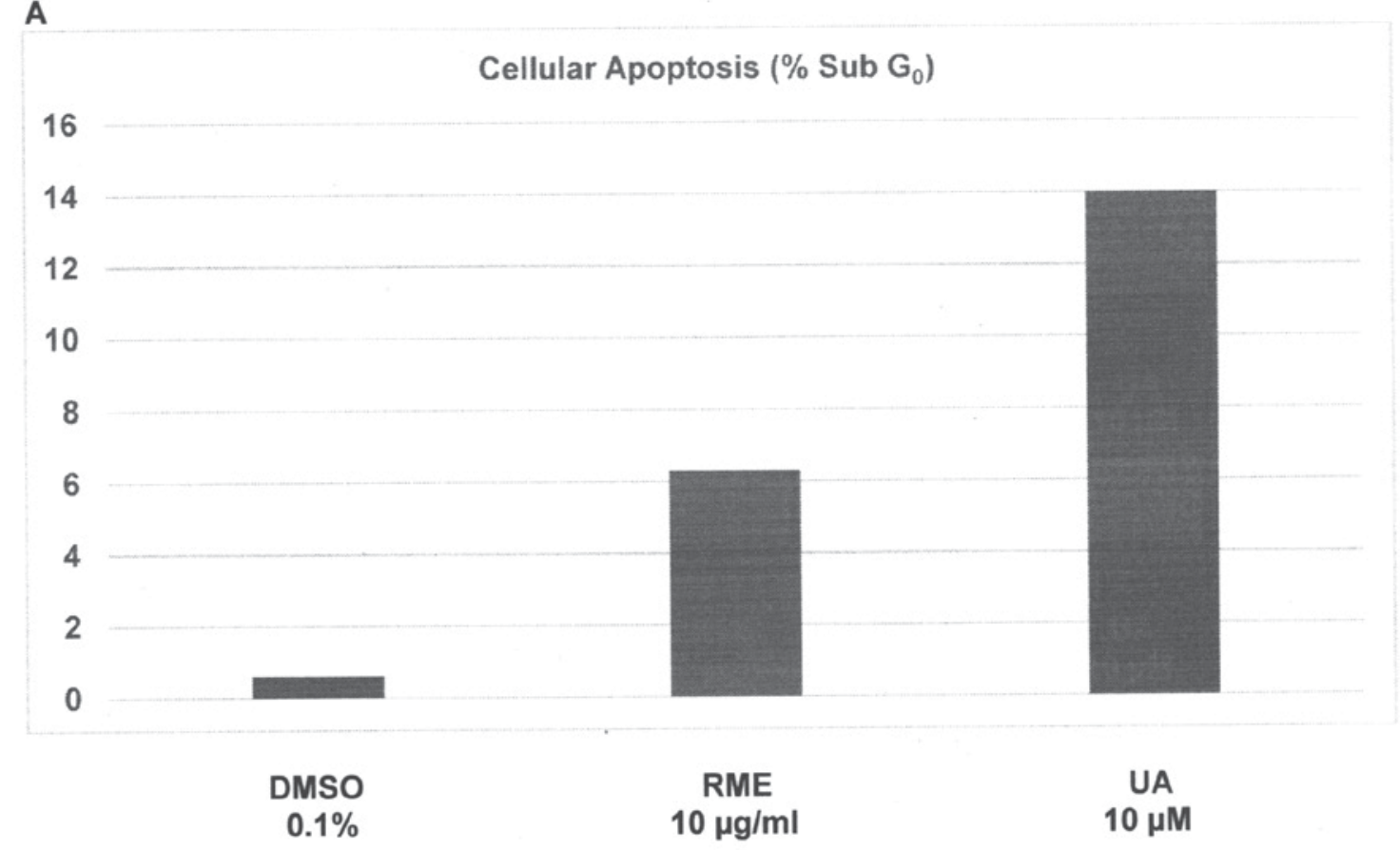

B

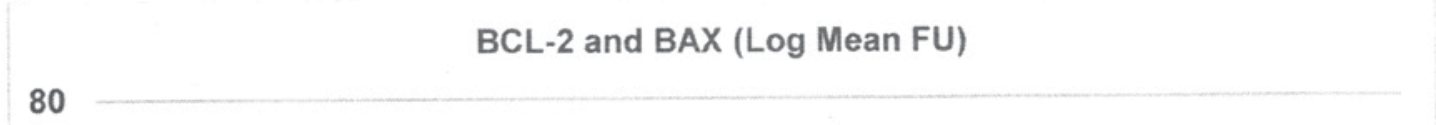

80

70

60

50

1
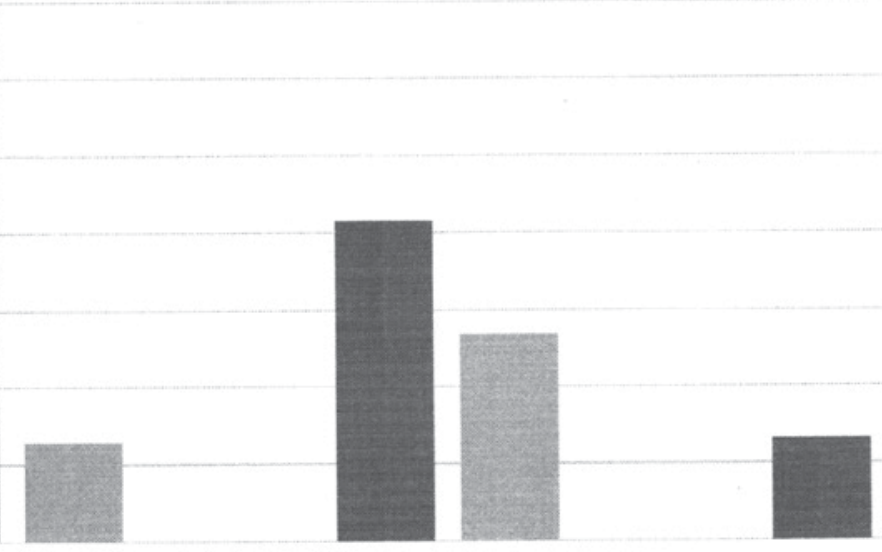

BCL-2 BAX

DMSO

RME

$0.1 \%$

$10 \mu \mathrm{g} / \mathrm{ml}$

UA

$10 \mu \mathrm{M}$

Figure 2. Induction of cellular apoptosis by RME and UA. (A) Treatment with RME and UA induces an increase in the sub-G G $_{0}$ (apoptotic) cells. Results are presented as the mean $\pm \mathrm{SD}, \mathrm{n}=6$ per treatment group. DMSO vs. RME $\mathrm{P}=0.01$, DMSO vs. UA $\mathrm{P}=0.01$. (B) Treatment with RME and UA demonstrated a decrease in anti-apoptotic Bcl-2 expression, and an increase in pro-apoptotic Bax expression. Results are presented as the log mean $\mathrm{FU} \pm \mathrm{SD}, \mathrm{n}=6$ per treatment group. Bcl-2: DMSO vs. RME, $\mathrm{P}=0.04$; DMSO vs. UA, $\mathrm{P}=0.02$. Bax: DMSO vs. RME, $\mathrm{P}=0.02$; DMSO vs. UA, $\mathrm{P}=0.02$. FU, fluorescence units; DMSO, dimethyl sulfoxide; RME, rosemary extract; UA, ursolic acid; Bcl-2, B-cell lymphoma-2; Bax, Bcl-2-associated X protein; SD, standard deviation.

decreased the number of AI colonies in a dose-dependent manner. This dose-response experiment identified individual $\mathrm{IC}_{50}$ concentrations of the compounds and identified a rank order for the inhibitory efficacy of CSOL $>$ CA $>$ RME $>$ UA.

The $\mathrm{IC}_{90}$ non-toxic concentration of RME was identified to be $10 \mu \mathrm{g} / \mathrm{ml}$. The maximum effective non-toxic concentrations for individual terpenoids were determined as $10 \mu \mathrm{M}$ for UA, $10 \mu \mathrm{M}$ for CA and $5 \mu \mathrm{M}$ for CSOL. These concentrations contain $4.57 \mu \mathrm{g} / \mathrm{ml} \mathrm{UA}, 3.32 \mu \mathrm{g} / \mathrm{ml} \mathrm{CA}$ and $1.65 \mu \mathrm{g} / \mathrm{ml} \mathrm{CSOL}$, respectively; thus, a comparison of the concentrations $(\mu \mathrm{g} / \mathrm{ml})$ of RME and the three terpenoids indicates that the proliferation inhibitory efficacy of RME may be partially due to combined effects of these mechanistically distinct terpenoids, which are present in differing concentrations in RME.

Experiments designed to examine the effects RME and UA on cell cycle progression of 184-B5/HER cells demonstrated 
A

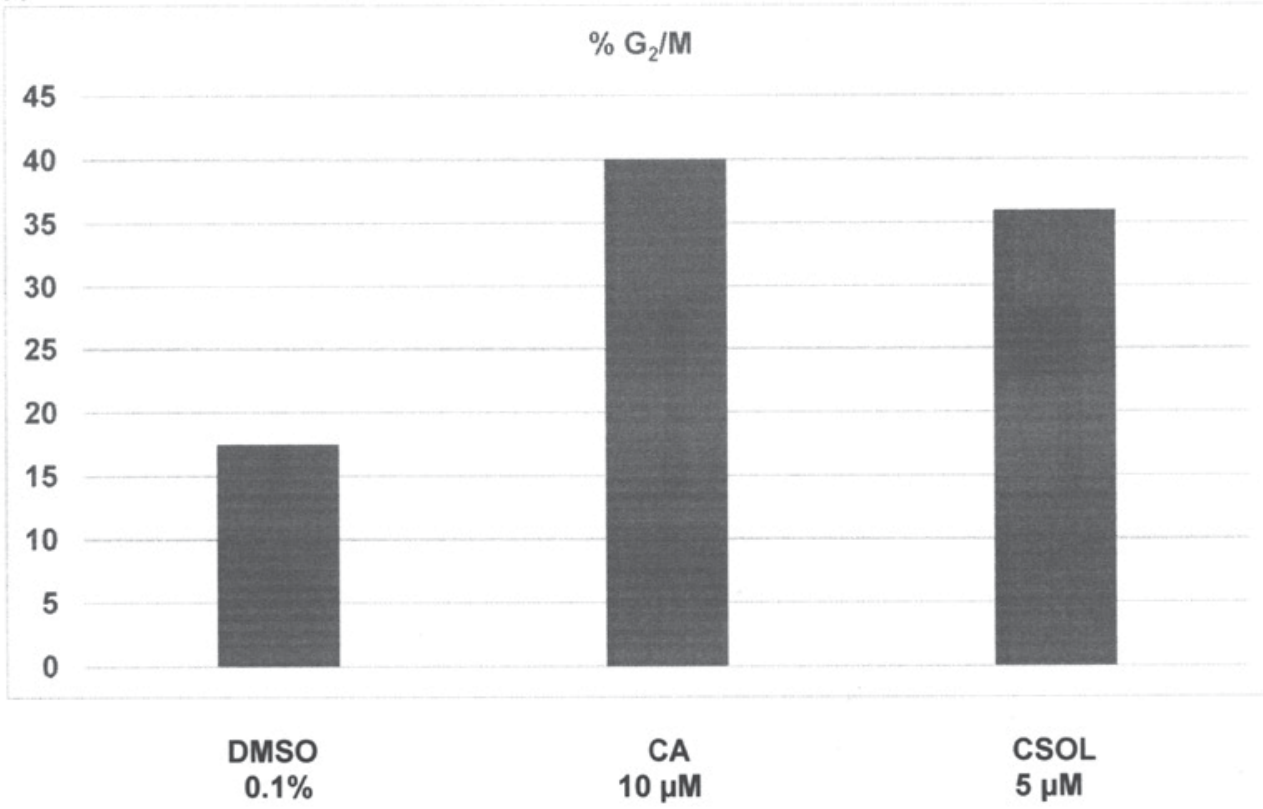

B

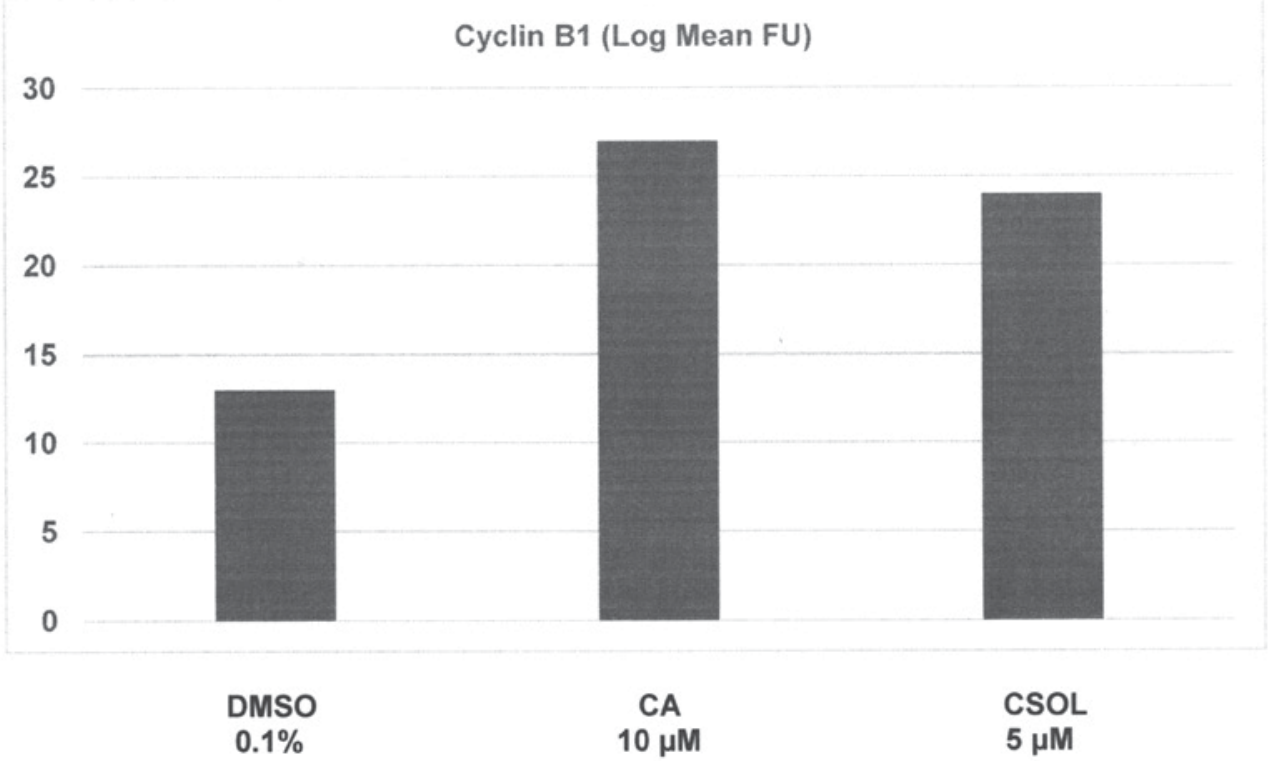

Figure 3. Regulation of cell cycle progression by CA and CSOL. (A) Treatment with CA and CSOL elicited an increase in $\mathrm{G}_{2} / \mathrm{M}$ arrest. Results are presented as the mean $\pm \mathrm{SD}, \mathrm{n}=6$ per treatment group. DMSO vs. $\mathrm{CA}, \mathrm{P}=0.03$; DMSO vs. $\mathrm{CSOL}, \mathrm{P}=0.03$. (B) Treatment with CA and CSOL resulted in an increase in the $\mathrm{G}_{2}$ phase-specific cyclin $\mathrm{B} 1$ expression. Results are presented as the log mean $\mathrm{FU} \pm \mathrm{SD}, \mathrm{n}=6$ per treatment group. DMSO vs. CA, $\mathrm{P}=0.02 ; \mathrm{DMSO}$ vs. CSOL, $\mathrm{P}=0.02$. FU, fluorescence units; DMSO, dimethyl sulfoxide; $\mathrm{CA}$, carnosic acid; $\mathrm{CSOL}$, carnosol; SD, standard deviation.

that RME, as well as UA, increased the $\mathrm{G}_{1}: \mathrm{S}+\mathrm{G}_{2} / \mathrm{M}$ ratio and decreased cyclin D1 expression. These data indicated inhibition of cell cycle progression via inhibition of cyclin D1-dependent $G_{1}$ to $S$ phase transition and resultant $G_{1}$ phase arrest. The pro-apoptotic effects of RME and UA in the present study were demonstrated by an increase of cell population in the sub- $\mathrm{G}_{0}$ phase of the cell cycle, decreased expression of anti-apoptotic Bcl-2 and increased expression of pro-apoptotic Bax proteins.

Notably, RME terpenoids are effective in proliferation inhibition of cancer cells via multiple mechanistic pathways; thus, RME inhibits P-glycoprotein activity and reverses multi-drug resistance in hormone receptor-positive MCF-7 cells (24). Rosemary terpenoid UA has documented inhibitory efficacy against transcriptional activity of tumor promoter-inducible cyclooxygenase-2 (COX-2) via extracellular-signal-regulated kinases 1/2 (ERK1/2), c-Jun N-terminal kinase (JNK) and p38 mitogen-activated protein kinase (MAPK) pathways in 184-B5/HER cells (14). In ER $\alpha$-/PR-positive MCF-7 cells, proliferation inhibitory activity of UA is due to induction of apoptosis via the intrinsic mitochondrial pathway, involving the downregulation of Bcl-2 (25). Additionally, UA promotes the induction of autophagy, apoptosis, and anti-inflammatory responses via 
the suppression of phosphoinositide 3-kinase/protein kinase $\mathrm{B}$ and nuclear factor- $\kappa \mathrm{B}$ pathways in a number of cellular models for breast cancer (26).

Experiments designed to examine the effects of CA and CSOL demonstrated that in comparison with RME and UA, these terpenoids induced $\mathrm{G}_{2} / \mathrm{M}$ phase arrest in 184-B5/HER cells and upregulated the expression of the $G_{2}$ phase-specific cyclin B1. Consistent with the present results, published evidence has demonstrated that hydrophobic herbal flavonoids induce $\mathrm{G}_{2} / \mathrm{M}$ phase arrest and upregulated the expression of cyclin B1 in colorectal adenocarcinoma-derived HCT-116 and HT-29 cell lines (27). In the colorectal adenocarcinoma-derived Caco- 2 cell line, CSOL and CA induce $\mathrm{G}_{2} / \mathrm{M}$ phase arrest via distinct modulation of increased cyclin $\mathrm{B} 1$ or decreased cyclin A levels (28). Furthermore, treatment of HER-2-expressing breast cancer cells with trastuzumab-emtansine (T-DM1) conjugate upregulates cyclin B1 expression in T-DM1-sensitive, but not resistant, phenotypes (29); thus, high levels of cyclin $B 1$ in $G_{2} / M$ arrested cells raise the possibility that proteasome-mediated degradation of the $\mathrm{G}_{2}$-specific cyclin may be impaired resultant to treatment with CA and CSOL. Furthermore, CA has been documented to synergize the antitumor activity of trastuzumab in HER-2-positive breast cancer cells (30), and CSOL has been identified to function as a potent inhibitor of transcriptional activation of inducible COX-2 and of prostaglandin production in 184-B5/HER cells. The mechanisms for efficacy of CSOL in this model involve protein kinase C, ERK1/2, JNK and p38-associated MAPK pathways (15). Collectively, the results of the present study provide evidence that the proliferation inhibitory efficacy of RME, UA, CA and CSOL is due to their selective effects on distinct phases of cell cycle progression and/or induction of cellular apoptosis via multiple context-dependent molecular mechanisms.

The results of the present study validate an experimental approach to identify clinically relevant mechanistic leads for efficacy of naturally occurring phytochemicals that may represent testable alternatives for treatment of HER-2-enriched breast cancer.

\section{Acknowledgements}

The author wishes to acknowledge active participation of Dr Hiromitsu Jinno from the Keio University School of Medicine, (Tokyo, Japan), Dr Melissa Steiner from the Weill-Cornell Medical College, (New York, NY, USA) and Dr Elizabeth Offord from the Nestlé Research Center, (Lausanne, Switzerland) in the research program entitled 'Cellular models for molecular subtypes of clinical breast cancer: Mechanistic approaches for lead compound efficacy'.

\section{Funding}

The present study was supported by the US National Cancer Institute (NCI) FIRST Award (grant no. CA 44741), Program Project Grant (grant no. PO1-CA 29502), NCI Contract Research Master Agreement (grant no. CN 75029-63), Department of Defense Breast Cancer Research Program IDEA Award (grant no. DAMD-17-94-J-4208), and by philanthropic funds to Strang Cancer Prevention Center.

\section{Availability of data and materials}

The datasets used and/or analyzed during the current study are available from the corresponding author on reasonable request.

\section{Authors' contributions}

The author contributed towards study conception, experimental design, data analysis, data interpretation, and prepared the manuscript for publication.

\section{Ethics approval and consent to participate}

Not applicable.

\section{Patient consent for publication}

Not applicable.

\section{Competing interests}

The author declares that there are no competing interests.

\section{References}

1. Sorlie T, Perou CM, Tibshirani R, Aas T, Geisler S, Johnsen H, Hastie T, Eisen MB, vande Rijn M, Jefrrey SS, et al: Gene expression patterns in breast carcinomas distinguish tumor subclasses with clinical implications. Proc Natl Acad Sci USA 98: 10869-10874, 2001.

2. Pierce JH, Arnstein P, DiMarco E, Artrip J, Kraus MH, Lonardo F, DiFiore PP and Aaronson SA: Oncogenic potential of erB-2 in human mammary epithelial cells. Oncogene 6: 1189-1194, 1991.

3. Telang NT, Narayanan R, Bradlow HL and Osborne MP: Coordinated expression of intermediate markers for tumorigenic transformation in Ras transfected mouse mammary epithelial cells. Breast Cancer Res Treat 18: 155-163, 1991.

4. Telang NT, Osborne MP, Sweterlitsch L and Narayanan R: Neoplastic transformation of mouse mammary epithelial cells by deregulated myc expression. Cell Regul 1: 863-872, 1990.

5. Johnston SRD and Dowsett M: Aromatase inhibitors for breast cancer: Lessons from the laboratory. Nat Rev Cancer 3: 821-831, 2003.

6. Romond EH, Perez EA, Bryant J, Suman VJ, Geyer CE Jr, Davidson NE, Tan-Chiu E, Martino S, Paik S, Kaufman PA, et al: Trastuzumab plus adjuvant chemotherapy for operable HER-2 positive breast cancer. N Engl J Med 353: 1673-1684, 2005.

7. Baselga $J$ and Swain SM: Novel anti-cancer targets: Revisiting ERB2 and discovering ERB3. Nat Rev Cancer 9: 463-475, 2009.

8. Lee KW, Bode AM and Dong Z: Molecular targets of phytochemicals for cancer prevention. Nat Rev Cancer 11: 211-218, 2011.

9. Ye I, Jia Y, JI KE, Sanders AJ, Xue K, Ji J, Mason MD and Jiang WG: Traditional Chinese medicine in the prevention and treatment of breast cancer and cancer metastasis. Oncol Lett 10: 1240-1250, 2015.

10. Subbaramaiah K, Chung WJ, Michaluart P, Telang N, Tanabe T, Inoue H, Jang M, Pezzuto JM and Dannenberg AJ: Resveratrol inhibits cyclo-oxygenase- 2 transcription and activity in phorbol ester treated human mammary epithelial cells. J Biol Chem 273: 21875-21882, 1998.

11. Katdare M, Osborne MP and Telang NT: Soy isoflavone genestein modulates cell cycle progression and induces apoptosis in HER2/neu oncogene expressing human breast epithelial cells Int J Oncol 21: 809-815, 2002.

12. Katdare M, Osborne MP and Telang NT: Novel cell culture models for prevention of human breast cancer (Review). Int J Oncol 22: 509-515, 2003.

13. Jinno H, Steiner MG, Nason-Burchenal K, Osborne MP and Telang NT: Preventive efficacy of receptor class selective retinoids on HER-2/neu oncogene expressing pre-neoplastic human mammary epithelial cells. Int J Oncol 21: 127-134, 2002. 
14. Subbaramaiah K, Michaluart P, Sporn MB and Dannenberg AJ: Ursolic acid inhibits cyclo-oxygenase-2 transcription in human mammary epithelial cells. Cancer Res 60: 2399-2404, 2000.

15. Subbaramaiah K, Cole PA and Dannenberg AJ: Retinoids and carnosol suppress cyclo-oxygenase-2 transcription by CREB-binding protein/p300-dependent and -independent mechanisms. Cancer Res 62: 2522-2530, 2002.

16. Manez S, Recio MC, Giner RM and Ríos JL: Effect of selected triterpenoids on chronic dermal inflammation. Eur J Pharmacol 334: 103-105, 1997.

17. Huang MT, Ho CT, Wang ZY, Ferraro T, Lou YR, Stauber K, Ma W, Georgiadis C, Laskin JD and Conney AH: Inhibition of skin tumorigenesis by rosemary and its constituents carnosol and ursolic acid. Cancer Res 54: 701-708, 1994.

18. Stampfer MR and Bartley JC: Induction of transformation and continuous cell lines from normal human mammary epithelial cells after exposure to Benzo $(\alpha)$ pyrene. Proc Natl Acad Sci USA 82: 2394-2398, 1985.

19. Zhai YF, Biettenmiller H, Wang B, Gould MN, Oakley C, Esselman WL and Welsch CW: Increased expression of specific tyrosine phosphatases in human breast epithelial cells neoplastically transformed by the neu oncogene. Cancer Res 53: 2272-2278, 1993.

20. Musgrove EA and Sutherland RL: Biological determinants of endocrine resistance in breast cancer. Nat Rev Cancer 9: 631-643, 2009.

21. Wang J, Gildea JJ and Yue W: Aromatase over-expression induces malignant changes in estrogen receptor- $\alpha$ negative MCF-10A cells. Oncogene 32: 5233-5240, 2013.

22. Telang N: Putative cancer initiating stem cells in cell culture models for molecular subtypes of clinical breast cancer. Oncol Lett 10: 3840-3846, 2015.

23. Telang N: Growth inhibitory efficacy of natural products in a model for triple negative molecular subtype of clinical breast cancer. Biomed Rep 7: 199-204, 2017.
24. Plouzek CA, Ciolino HP, Clarke R and Yeh GC: Inhibition of P-glycoprotein activity and reversal of multidrug resistance in vitro by rosemary extract. Eur J Cancer 35: 1541-1545, 1999.

25. Kassi E, Sourlingas TG, Spiliotaki M, Papoutsi Z, Prastinis H, Aligiannis $\mathrm{N}$ and Moutsatsou P: Ursolic acid triggers apoptosis and BCL-2 down-regulation in MCF-7 breast cancer cells. Cancer Investig 27: 723-733, 2009.

26. Lou J, Hu YL and Wang H: Ursolic acid inhibits breast cancer growth by inhibiting proliferation, inducing autophagy and apoptosis, and suppressing inflammatory responses via the PI3K/AKT and NFkB signaling pathways in vitro. Exp Ther Med 14: 3623-3631, 2017

27. Wang CZ, Calway TD, Wen XD, Smith J, Yu C, Wang Y, Mehendale SR and Yuan CS: Hydrophobic flavonoids from Scutellaria baicelensis induce colorectal cancer cell apoptosis through a mitochondrial-mediated pathway. Int J Oncol 42: 1018-1026, 2013

28. Vissanji JM, Thompson DG and Padfield PJ: Induction of G2/M phase cell cycle arrest by carnosol and carnosic acid is associated with alteration of cyclin A and cyclin B1 levels. Cancer Lett 237: 130-136, 2006.

29. Sabbaghi MA, Gil-Gomez G, Guardia C, Servitja S, Arpi O, Garcia-Alonso S, Menedez S, Arumi-Uria M, Serrano L, Salido M, et al: Defective cyclin B1 induction in trastuzumab-emtansine (T-DM1) acquired resistance in HER-2 positive breast cancer. Clin Cancer Res 23: 7006-7019, 2017.

30. D'Alesio C, Bellese G, Gagliani MC, Aiello C, Grasselli E, Marcocci G, Bisio A, Tavella S, Daniele T, Cortese K and Castagnola P: Cooperative anti-tumor activities of carnosic acid and Trastuzumab in ERBB2 ${ }^{+}$breast cancer cells. J Exp Clin Cancer Res 36: 154, 2017. 